\title{
Turismo e fronteira: integração cultural e tensões identitárias na divisa do Brasil com o Paraguai
}

\section{Álvaro Banducci Júnior ${ }^{i}$}

Universidade Federal de Mato Grosso do Sul

Resumo: As fronteiras espaciais são contextos significativos de demarcação de diferenças e de classificações da alteridade entre povos e culturas contíguos. Constituem-se em locais de integração e de hibridismos e ao mesmo tempo em ambiente de conflitos. A atividade turística, de forma semelhante, ao movimentar grandes contingentes humanos, em busca de lazer e de entretenimento, propicia o contato freqüente entre povos e culturas, desencadeando distintos contextos de diálogo e de confronto intercultural. Constituem-se assim, tanto os territórios geográficos limítrofes quanto os territórios turísticos, em espaços formadores de fronteiras simbólicas, contextos privilegiados para a investigação da natureza das identidades, na medida em que fomentam relações de alteridade e a dinâmica das representações de si e do "outro". Este trabalho visa discutir o modo como o turismo, num território de fronteira política, nas cidades gêmeas de Ponta Porã (BR) e Pedro Juan Caballero (PY), tem contribuído para instituir contextos de fronteiras simbólicas em Mato Grosso do Sul.

Palavras-chave: Fronteira; Turismo; Diálogo cultural; Confronto; Identidade.

Title: Tourism and frontiers: cultural integration and identity tension at Brazil -Paraguay border

Abstract: Spatial boundaries are significant contexts for the demarcation of difference and otherness between adjacent peoples and cultures. They consist of local integration and hybrids, but also are environments of conflict. Tourism, while moving large numbers of human beings in search of leisure and entertainment, provides also frequent contacts between peoples and cultures, triggering distinct contexts of intercultural dialogue and confrontation. So geographic frontier territories as well as tourism territories turn into places of symbolic boundaries, privileged contexts for investigating the nature of identities, to the extent that they foster relations of otherness and the dynamics of representations of self and "other “. This paper aims to discuss how tourism, in a territory of frontier at the twin cities of Ponta Pora (BR) and Pedro Juan Caballero (PY), has helped to establish the contexts of symbolic boundaries in Mato Grosso do Sul

Keywords: Frontier; Tourism; Cultural dialogue; Confrontation; Identity. 


\section{Introdução}

Antropólogos, envolvidos com a temática do turismo, têm dedicado especial atenção à mobilidade de grandes contingentes humanos, em busca de lazer e de entretenimento, e dos efeitos desses deslocamentos sobre as sociedades receptoras e sobre os próprios viajantes e seu ambiente de origem. Como tal, os estudos nesse campo da antropologia têm trazido novos e instigantes elementos para as discussões sobre contatos, trocas e conflitos étnicos e sociais, que têm lugar nas sociedades humanas, ao mesmo tempo em que apontam para novas abordagens sobre temas caros à antropologia, tais como mudança cultural, autenticidade, identidade, etnicidade, entre outros.

O enfoque dessas pesquisas freqüentemente circunscreve-se ao âmbito das populações em contato, tratando, sobretudo, dos impactos sofridos pelas populações receptoras em decorrência da presença estrangeira. As reações desses grupos quando em interação com estrangeiros, as mudanças e resistências sociais e culturais que mobilizam diante do "outro", as releituras e ressignificações de seus valores são, do mesmo modo, objeto de estudo de sociólogos e antropólogos. Mas, a presença do turismo não apenas promove o contato do "nativo" com o estrangeiro, desencadeando processos culturais de interação e de resistência, mas constitui-se num mecanismo complexo de criação de barreiras sociais e espaços liminares, seja de tensão ou encantamento, que muito se aproximam das situações de fronteiras políticas e espaciais, que se materializam nos contextos mais diversos onde se desenvolve a atividade.

De um lado, ao promover o contato entre povos distintos constitui um território fértil em relações de alteridade, importante para se conhecer a dinâmica das identidades, pois ao mesmo tempo em que interagem as culturas dialeticamente afirmam suas diferenças e contradições. De outro, insere as localidades no contexto do mercado global e da cultura mundializada, desencadeando processos de interações transnacionais, de dimensões significativas, que mobilizam parâmetros e representações locais e de âmbito nacional a fim de dialogar e se contrapor às referências externas.

Partindo desse princípio, de que o turismo é um formador de fronteiras, este trabalho se propõe buscar, nos enfoques antropológicos dispensados à análise e compreensão das relações fronteiriças, elementos que sirvam como indicadores que auxiliem na interpretação de novas dimensões do fenômeno turístico. Para tanto se vale de uma experiência turística em território fronteiriço sul-mato-grossense, a que acontece na divisa entre Ponta Porã (BR) e Pedro Juan Caballero (PY).

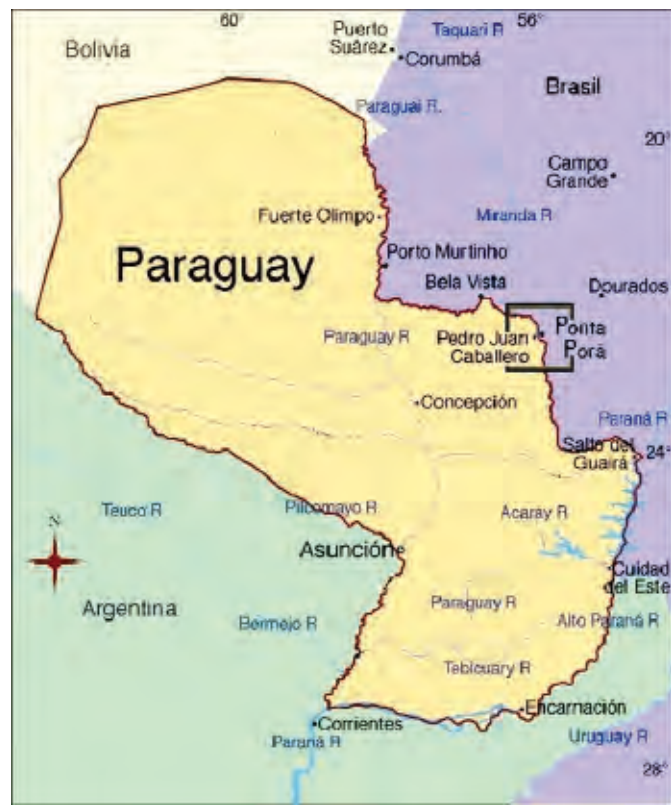

Localização das cidades fronteiriças de Pedro Juan Caballero (PY) e Ponta Porã (BR). (Fonte: www.google.com.br/ imgres?imgurl=http://www.biblioteca.ifc-camboriu.edu.br - modificado; 2011).

\section{Fronteira: breve aporte conceitual}

A noção de fronteira não raro é associada à idéia de limite, de barreira, que determina territórios e estabelece descontinuidades, impedindo a livre comunicação e contato entre os povos que habitam 
esses espaços. De outro lado, a visão romântica associa fronteira a populações unidas fraternalmente, ainda que separadas por uma linha divisória que lhes é exteriormente imposta. Mais que isso, porém, a fronteira, como salienta Raffestin (2005), é um fato social de uma riqueza considerável, que compreende aspectos físicos, morais, políticos, religiosos e culturais de diversas ordens. É um espaço de tensão e contradição entre aquele que cruza a fronteira e o que a reforça (Albuquerque, 2009).

No campo da antropologia, se, há muitas décadas ${ }^{1}$, a temática da fronteira desperta a atenção de seus pensadores, é a partir do final do século XX e início do século XXI, com o advento da chamada globalização e dos processos a ela associados - tais como a migração intensa, a ampliação das zonas de contato e, em contrapartida, as imposições de barreiras territoriais e identitárias - que o tema ganha destaque e inspira um volume crescente de investigações.

As pesquisas voltaram-se para o levantamento e interpretação das microrrelações e das trocas econômicas e culturais que acontecem em decorrência dos fluxos transfronteiriços de bens, pessoas e símbolos e, da mesma forma, preocuparam-se em identificar o papel dos territórios e das populações "periféricos/as" na construção do estado e da nacionalidade, que antes restringiam-se às zonas consideradas centrais. De acordo com Grimson (2005),

o enfoque contemporâneo, que estimu-

la esses estudos, visa analisar como as negociações identitárias nas fronteiras afetam a construção de novos sentidos da nacionalidade e, inversamente, como as novas políticas definidas desde os centros político-econômicos transformam a vida cotidiana e a experiência das populações locais (p. 22).

É nesse aspecto que, ao ressaltar a importância do estudo da fronteira, Sahlins (2000) destaca a sua contribuição no sentido de evidenciar o papel dos grupos locais como agentes e atores históricos na formação de identidades e territórios.

Encontrar nas fronteiras - nacionais ou turísticas - espaços dinâmicos e democráticos, de livre circulação e contato intenso entre pessoas e culturas é, desse modo, tão factível e produtivo para a análise quanto revelar os elementos que identificam e mantêm separados os grupos em interação. $\mathrm{O}$ conceito de fronteira étnica tem se mostrado uma ferramenta teórica importante no sentido de alertar o pesquisador, em meio à complexidade que permeia os ambientes de contato cultural intenso, para a necessidade de se ater tanto aos setores de articulação local quanto às dicotomias dos sistemas que investiga. Tal como afirma Fredrik Barth (1998: 196)

onde indivíduos de culturas diferentes interagem poder-se-ia esperar que [as] diferenças se reduzissem, uma vez que a interação simultaneamente requer e cria uma congruência de códigos e valores [...] Assim, a persistência de grupos étnicos em contato implica não apenas critérios e sinais de identificação, mas igualmente uma estruturação da interação que permite a persistência das diferenças culturais

Ao se perceberem como estrangeiros, os grupos étnicos [compostos de pessoas que compartilham comportamentos e critérios de avaliação e julgamento particulares], reconhecem diferenças que os singularizam. Interesses, valores, juízos acerca do outro, são parâmetros exercitados no dia-a-dia e que tendem a limitar as interações sociais, ao mesmo tempo que reforçam a coesão interna dos grupos em contato.

A relevância da contribuição de Barth para o estudo da fronteira advém desse autor separar como distintas, em seus estudos sobre identidade étnica, a dimensão da 'organização social' e da cultura (Cardoso de Oliveira e Baines, 2005). Barth argumenta que a ordem cultural pode mudar significativamente sem que mudanças equivalentes ocorram na identidade étnica do grupo, tal como Cardoso de Oliveira demonstrou em relação aos Terena que, mesmo havendo migrado para as cidades, mantinham suas referências identitárias indígenas. 
Isso significa que a natureza da identidade étnica não guarda qualquer homologia com a da cultura, ainda que ambas mantenham estreita interação. A rigor, os elementos ditos culturais sempre estarão a serviço da identidade como sinais diacríticos, diferenciadores, manejados pelos indivíduos e grupos para marcar simbolicamente suas respectivas especificidades (Cardoso de Oliveira e Baines, 2005: 11).

Os sistemas interétnicos, por seu lado, guardam, em termos estruturais, estreita relação com os sistemas de interação entre nacionalidades, tal como os que ocorrem em áreas de fronteira internacional. Para Grimson (2000), a noção de fronteira étnica, tal como definida por Barth, é bastante útil no estudo das fronteiras interestatais, na medida em que as identidades fronteiriças, numa situação de contato permanente entre povos, não necessariamente remetem ao compartilhar de símbolos e referências homogêneas, mas, ao contrário, mesmo quando sujeitas a influências culturais e de mercado externas pautadas em lógica semelhante, são as suas diferenças e singularidades que se vêem estimuladas no âmbito das relações cotidianas (Grimson, 2000). O autor entende, no entanto, que a fronteira étnica é um fenômeno situacional e não primordial na análise das relações transfronteiriças. Para ele, é necessário considerar que as fronteiras são produto de acordos históricos e de relações de força que dizem respeito não apenas às populações locais, mas expressam políticas e relações de força de estados nacionais. Assim, não se deve ignorar, na análise das realidades transfronteiriças, as relações centro-periferia que acontecem em âmbito nacional, atentando para as influências dos centros de poder na vida dos núcleos de fronteira, bem como as políticas internacionais que influenciam nas decisões internas de cada nação.

Cardoso de Oliveira, por sua vez, corrobora essa visão afirmando que, no caso da situação de fronteira, mais do que a etnicidade, o determinador social, político e cultural, passa a ser a nacionalidade dos agentes sociais. $\mathrm{O}$ antropólogo chama a atenção para a existência de um quadro de referência internacional, configurado por um processo transnacional, que aponta para o caráter dinâmico das relações sociais nesses territórios limítrofes. Assim, como diz o autor,

da mesma maneira que na confrontação entre identidades étnicas (...), agora, no caso de nacionalidades, será num espaço internacional marcado pela contigüidade de nacionalidades distintas (e no interior dessas, supostamente, de etnias diversas) que surge o foco privilegiado de investigação: não mais o sistema interétnico, (...) mas o sistema inter e transnacional, visto em termos das nacionalidades em conjunção (Cardoso de Oliveira e Baines, 2005: 15).

Pode-se inferir, com base no que foi exposto até o momento, que as fronteiras constituem, primeiramente, espaços de contato social e de intercâmbio cultural, ao mesmo tempo em que são territórios de tensão e contradições. Estão ligadas aos centros político-econômicos de cada país, sofrendo influências das políticas nacionais e, ao mesmo tempo, contribuindo para a construção de novos sentidos de nacionalidade. Por fim, que operam conforme determinações de políticas inter e transnacionais, cujas flutuações orientam comportamentos e sentimentos mútuos na vida cotidiana dos núcleos humanos contíguos. Em outros termos, as fronteiras compreendem redes de relações e de influências sociais, culturais e políticas que transcendem os espaços locais para abranger contextos nacionais e internacionais mais amplos.

O turismo, da mesma forma, na medida em que propicia o contato entre distintas culturas, não apenas promove o encontro e o diálogo de identidades, mas cria ambientes de negociações e conflitos sociais, de resistência e confrontos políticos que advêm de condições históricas internas, assim como das contradições colocadas pela situação de contato entre sociedades e culturas diversas. O benefício de se recorrer ao enfoque das fronteiras para se compreender essas dimensões do 
fenômeno turístico, decorre, pois, do fato de remeter a um contexto que expõe tensões dialéticas tanto das relações locais e cotidianas quanto da modernidade ocidental, que impõe a presença estrangeira, sua cultura e referência de mundo, e a lógica de mercado que regulamenta sua presença. Se o turismo desencadeia tais redes de relações e significados, o faz, sobretudo, em decorrência das situações de confronto social e cultural que promove entre povos distantes, criando contextos liminares e tensos, próprios dos espaços fronteiriços. Cabe, por fim, revelar como

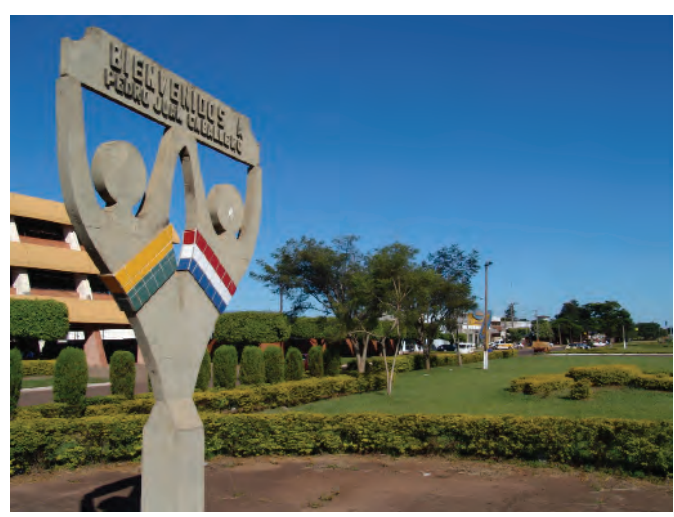

Marco divisório das cidades conurbadas de Ponta Porã (BR) e Pedro Juan Caballero (PY). (Foto: Álvaro Banducci Jr. 2008).

esta situação se manifesta empiricamente a partir da observação de um empreendimento turístico de Mato Grosso do Sul.

\section{Fronteira Brasil - Paraguai e o Tu- rismo em Pedro Juan Caballero (PY)}

A experiência a ser observada neste estudo é a do turismo que se desenvolve em território de fronteira entre o Mato Grosso do Sul e o Distrito de Amambay (PY), compreendendo as cidades gêmeas de Ponta Porã (BR) e Pedro Juan Caballero (PY). Esses dois núcleos caracterizam-se por um elevado e constante fluxo de pessoas e de mercadorias, facilitado por sua condição de conurbação. A linha de fronteira, que demarca o limite internacional no contexto urbano, constitui-se numa estreita faixa de terra, com aproximadamente 13 km de extensão, tangenciada pela Avenida Internacional, no lado brasileiro, e pela
Rua Dr. Francia, no lado paraguaio. As duas cidades se desenvolveram ao longo dessa linha divisória, através da qual se estabeleceram as casas comerciais e as residências de paraguaios e de brasileiros (Lamberti e Oliveira, 2008).

A disposição das cidades permite o transitar constante da população através da linha de fronteira, em função de traba-

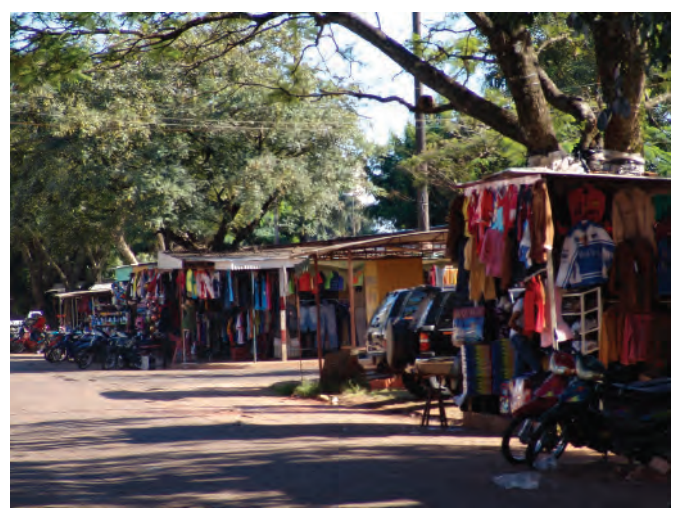

Mercado informal presente na principal via de comércio de Pedro Juan Caballero (PY). (Foto: Álvaro Banducci Jr. 2008)

lho ou em busca de serviços públicos, como saúde e educação, propiciando uma expressiva interação entre seus moradores, que compartilham vivências, costumes e valores, configurando o que os geógrafos costumam denominar territorialidade fronteiriça (Oliveira, 2005; Martins, 2007; Müller, 2008). A convivência pacífica não se traduz, entretanto, num convívio fraterno e harmonioso entre os povos paraguaio e brasileiro. Existe uma rivalidade histórica, que advém do período da Guerra com o Paraguai ${ }^{2}$, em função da qual são disseminadas imagens negativas do Brasil, visto como nação imperialista e usurpadora de territórios, enquanto que seu povo é tido como arrogante e presunçoso. Os brasileiros, por seu lado nutrem uma imagem do Paraguai como país atrasado, subdesenvolvido, com um povo pouco empreendedor, violento e desleal.

Essas representações e estereótipos são alimentados pela presença marcante do turismo de compras em Pedro Juan Caballero que, centrado no comércio de produtos importados, mobiliza a economia e o cotidiano das duas cidades, atraindo 


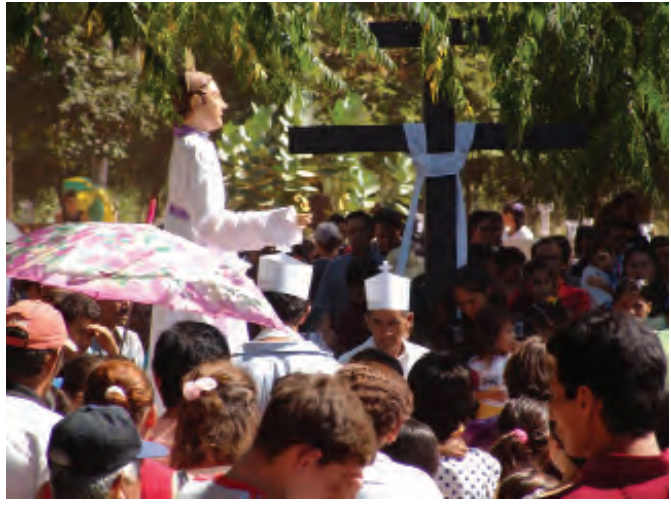

Celebração da Sexta-feira da Paixão no Paraguai. A população acorre em grande número aos cemitérios a fim de homenagear seus mortos, participar de cultos e rituais católicos e encontrarse com parentes e amigos. (Foto: Álvaro Banducci Jr., 2008)

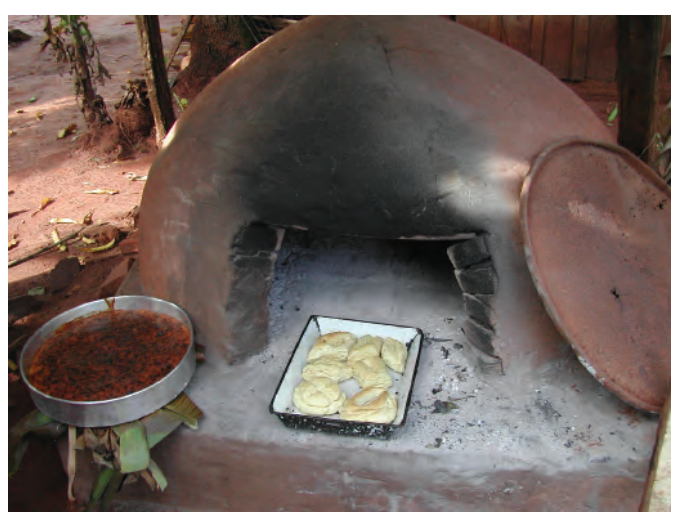

Tataquá com uma forma de sopa paraguaia (à esquerda) e de chipas (ao centro). (Foto: Álvaro Banducci Jr., 2005).

para a região um volume considerável de visitantes provenientes de Mato Grosso do Sul e de estados vizinhos. É também o turismo, e o comércio de importação a ele associado, que coloca esse pequeno território fronteiriço no contexto mais amplo da economia global e em sintonia com as novidades do mercado internacional. Juntamente com a importação de produtos da mais alta tecnologia atrai para a região capital estrangeiro, desencadeando um movimento migratório importante, que inclui comerciantes de origem árabe, asiática e brasileira que ali instalam pequenos negócios e empresas.

Esses investimentos mobilizam, por sua vez, trabalhadores fronteiriços brasileiros e do interior paraguaio, que para ali se dirigem em busca de oportunidades de emprego para si e seus familiares. $\mathrm{O}$ turismo, portanto, promove novos arranjos territoriais, mobilizando pessoas, capital e bens simbólicos, alimentando as referências sobre o "outro" e reordenando as situações de contato e interação. Do mesmo modo, induz a que práticas ilegais ou não regulamentadas, tais como o comércio informal e o contrabando, ganhem novos atores, que modificam as relações de força entre os mandatários locais, obrigando a sociedade a se ajustar às novas conformações sociais ditadas pelo crime e a ilegalidade.

As referências globais e a agitação do turismo em Pedro Juan Caballero, que impõem um ritmo acelerado ao ambiente do comércio local, contrastam com um cotidiano pacato e provinciano da cidade. De um lado, impera não apenas a referência tecnológica e a atualidade dos produtos, que por si mesmos exigem o domínio de uma linguagem específica e conhecimento técnico especializado, mas a lógica de sua comercialização, que impõe um ritmo diferenciado à vida do trabalhador, obrigando-o a mudar de hábitos e adaptar costumes para atender à demanda do comércio re-exportador. De outro lado, existe a vida imperturbável, que nas tardes calorentas atrai para as calçadas parentes e amigos nas "rodas de tereré"; ; há os quintais arborizados, com o imprescindível "tataquá", forno de barro no qual as donas-de-casa, em trabalho geralmente coletivo, assam os quitutes costumeiros, como chipa e sopa paraguaia ${ }^{4}$, para o consumo da família e das visitas; e existe a tradição religiosa de um povo, que ao mesclar elementos da cultura hispânica com a herança guarani, faz de suas celebrações religiosas ocasiões festivas e de forte devoção popular (Banducci e Romero, 2005). Os paraguaios são reconhecidos, inclusive pelos moradores de Ponta Porã, por seu fervor religioso, a ponto de atrair fiéis da cidade vizinha para participar de seus cultos e celebrações ${ }^{5}$.

Em meio a uma multiplicidade de referências simbólicas e temporais, de espacialidades que remetem a ritmos distintos e de territorialidades construídas a par- 
tir de processos de interação e confronto entre dois povos, o turismo, tanto desencadeia o diálogo intercultural quanto promove mobilizações internas, como processos migratórios, gerando tensões sociais e políticas, e acirrando os sentimentos nacionalistas, seja em relação aos brasileiros, vizinhos históricos, seja em relação aos novos imigrantes estrangeiros ali instalados em função do comércio de produtos importados. Os conflitos culturais entre imigrantes e nativos paraguaios, os estereótipos construídos nesse cenário de fronteiras simbólicas e territoriais e o quadro de expansão do capital tendem a acirrar as tensões entre as comunidades nacionais, orientando comportamentos e sentimentos específicos das populações de ambos os lados da fronteira, como se poderá observar nas experiências que se seguem.

\section{Migrações internas e fluxos frontei- riços}

Se a fronteira do Brasil com o Paraguai é local de trânsito permanente de bens e pessoas, uma série de outros fluxos têm lugar na divisa entre os dois países, desde o comércio de produtos ilícitos, o tráfico de drogas, até o movimento de capital e de força de trabalho estrangeiros. Nas últimas décadas, os movimentos migratórios, que acontecem nos dois sentidos da fronteira, têm contribuído para acirrar os conflitos entre os moradores fronteiriços.

O baixo preço da terra no Paraguai e a facilidade de crédito agrícola atraíram o interesse de latifundiários brasileiros que passaram a adquirir terras nos departamentos limítrofes do Brasil, dentre eles Canindeyú e Amambay que fazem divisa com Mato Grosso do Sul ${ }^{6}$. Juntamente com os grandes proprietários - e os trabalhadores por eles arregimentados para derrubar matas, plantar pastos ou cultivar os campos - houve uma considerável penetração de pequenos agricultores e arrendatários brasileiros que, em função de indenizações recebidas com a implantação da usina de Itaipu ${ }^{7}$, acabaram por adquirir terras e se instalar no Paraguai ${ }^{8}$.
A investida do capital sojicultor - grandes empresários produtores de soja, interessados em terras de baixo custo - sobretudo de origem brasileira, mas também alemã e italiana, provocou um processo de concentração de terras, que desencadeou um amplo movimento migratório do campo para a cidade, cujos efeitos se fizeram sentir na fronteira do Brasil com o Paraguai. De acordo com Albuquerque (2009), com a chegada do capital internacional,

A partir do final da década de 1970 e início dos anos 1980, ampliam-se os processos de mecanização e de concentração da propriedade da terra [na] faixa de fronteira. [...] Nesse contexto, aumentam as compras de terra aos camponeses paraguaios e aos pequenos produtores brasileiros. A pequena produção diversificada e de subsistência (milho, mandioca etc.) passa a ser substituída pelo plantio de soja. Nesse processo, começam os deslocamentos de camponeses paraguaios e brasileiros para outras frentes agrícolas no interior do Paraguai e para as periferias das cidades de fronteira (p. 143).

As cidades de Pedro Juan Caballero, Ciudad del Leste e Salto Guairá, na divisa com o Brasil, e Encarnación, na divisa com a Argentina (Oliveira, 2005 e Albuquerque, 2009), tornaram-se pólo de atração desses imigrantes camponeses, que chegam à cidade, após um período de resistência às frentes de expansão do capital no campo, trazendo as marcas de um confronto de dimensões não apenas de classe, mas internacional e civilizatório ${ }^{9}$.

As disputas entre camponeses e plantadores de soja se transformam num confronto entre brasileiros e paraguaios. Os sentimentos nacionalistas em relação ao território e à língua guarani e os ressentimentos do período da 'Guerra do Paraguai' afloram nos discursos dos camponeses paraguaios e os brasileiros são acusados de 'invasores', 'novos bandeirantes', 'herança de Stroessner' etc. (Albuquerque, 2009: 9).

Os imigrantes brasileiros, por seu lado, ao assumirem também uma postura nacionalista, disseminam, para 


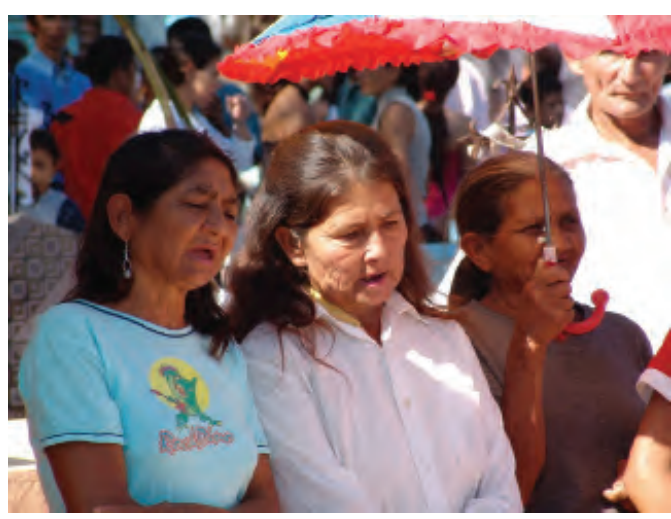

Estacioneras cantam em cemitério por ocasião da Sexta-feira da Paixão no Paraguai. (Foto: Álvaro Banducci Jr., 2008).

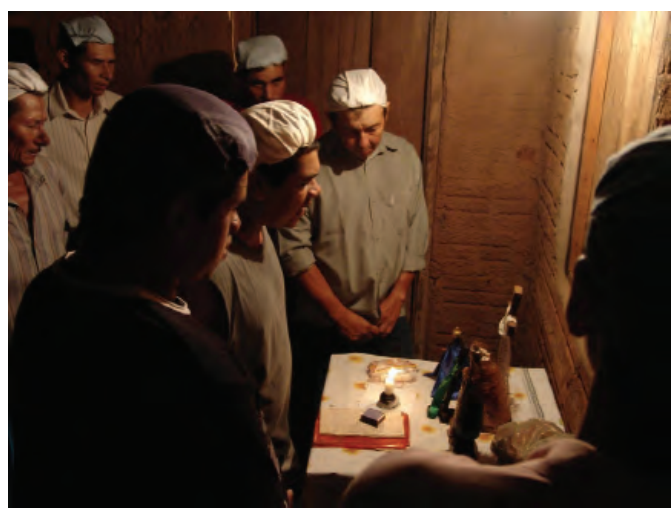

A presença de estacioneros se faz sentir também em território brasileiro, como na região rural de Bela Vista (MS), quando saem em romaria na noite da Quinta-feira Santa, detendo-se para rezar diante de altares previamente armados pela população para recebê-los. (Foto: Álvaro Banducci Jr,, 2009).

além do campo, uma imagem negativa do povo paraguaio, espelhados no que consideram ser sua superioridade tecnológica e cultural. Provenientes de um país moderno e desenvolvido, os bem-sucedidos fazendeiros e empresários brasileiros em terras paraguaias, compartilham o sentimento de serem eles próprios agentes redentores, missionários da civilização, exemplo de trabalho e pioneirismo a ser seguido pelos naturais da terra (Albuquerque, 2009).

As imagens do povo paraguaio, compartilhadas e difundidas pelos brasileiros, seja no contexto da disputa pela terra ou do mercado turístico, desencadeiam re- ações políticas e identitárias que confrontam as diferenças culturais e de poder. Como diz Albuquerque (2009), a auto-identificação dos imigrantes como 'trabalhadores', 'pioneiros' e a classificação dos paraguaios como 'preguiçosos', 'corruptos' e 'subdesenvolvidos' simbolizam assimetrias de poder entre as classes sociais e as nações. Mas as relações de poder entre os grupos sociais não são estáticas e consolidadas. Os grupos subordinados podem adquirir força política e atacar os interesses e as identidades dos grupos estabelecidos. A dinâmica de poder entre os grupos redefine as identidades coletivas (p 10).

Em meio às disputas políticas e identitárias, ao confronto cultural e nacionalista, o Brasil não raras vezes é acusado, nas vozes de políticos, sindicalistas e jornalistas paraguaios, de país imperialista (Sprandel, 2000). A língua, a história, as práticas religiosas, os valores e tradições do povo paraguaio, passam a ser, então, exaltados como parâmetro de nacionalidade frente ao avanço da cultura e da pretensa superioridade do "outro". À modernidade imposta pelo estrangeiro, narcísico e arrogante, contrapõe-se a tradição, um fator relevante de afirmação identitária e resistência ideológica.

No entanto, é essa mesma modernidade, negada, que se difunde, de forma crescente no ambiente do turismo, afetando o cotidiano do trabalhador do comércio de importados de Pedro Juan Caballero. Ele tende a articular e negociar com freqüência crescente as referências de significado em torno de um "nós" tradicional, que a princípio estaria apegado aos costumes e valores nacionais, e um "outro" moderno, pouco confiável e distante, porém tanto mais próximo desde que o trabalhador, ele próprio, tem seu cotidiano dominado por um contexto de mudanças que impõe de forma crescente a lógica da alteridade como parâmetro de mundo.

Se as contradições da modernidade repercutem e ganham sentido em âmbito local, a tradição, ou as práticas e valores que se constituem em parâmetro de representação da identidade local, pode 
induzir, também, a novos e inusitados arranjos sociais. $\mathrm{O}$ imigrante camponês, por exemplo, o elemento marginalizado ou, na perspectiva do trabalhador do comércio formal, o competidor desleal por atuar no comércio informal, pode se constituir no depositário dos valores mais caros à tradição e, como tal, no portador das referências simbólicas que se contrapõem à alteridade. Em pesquisas anteriores (Banducci Jr e Romero, 2005 e Banducci Jr e Amizo, 2009), identificou-se entre os trabalhadores da linha de fronteira, que haviam migrado havia pouco tempo para a cidade de Pedro Juan Caballero, alguns representantes ativos - não raro líderes - de práticas religiosas que vinham perdendo vigor na comunidade pedrojuanina, como é o caso dos rituais dos estacioneros, cantores das estações de Cristo que se apresentam por ocasião da Semana Santa em várias localidades do Paraguai. O domínio dessas práticas, profundamente arraigadas aos costumes religiosos do povo paraguaio, ainda que venham perdendo vitalidade, instrumentalizam esses trabalhadores nas negociações em torno de sua inserção no contexto social fronteiriço, constituindo eles próprios em depositários das referências mais caras da nacionalidade paraguaia.

Assim, compreender a experiência turística nesse espaço implica em conhecer os inúmeros fluxos, de pessoas e de capital que mobiliza, bem como os fluxos de significado que alimentam as redes de relações do povo paraguaio entre si e deste com os estrangeiros, sejam os vizinhos moradores de Ponta Porã (MS), sejam os turistas que para ali afluem em número crescente. Nesse contexto, dicotomias tais como centro e periferia, nacional e estrangeiro, rural e urbano, tradição e modernidade ganham novas articulações e sentido no âmbito, e por influência, do turismo, instaurando novos parâmetros de representação acerca de si e do outro.

\section{Conclusão}

No momento em que grandes projetos de integração regional se consolidam através do mundo, tais como União Européia, MERCOSUL, Nafta, Comunidade Andina (Masi, 2008), entre outros, alimentando discursos políticos e acadêmicos sobre um possível desaparecimento das fronteiras, autores como Rafestin (2005) e Oliveira (2005), no campo da geografia, e Canclini (1998), Grimson (2000 e 2005), Albuquerque (2009), entre outros nas ciências sociais, argumentam que se trata de um fenômeno bastante mais complexo e repleto de contradições. Conforme demonstram em seus estudos, mesmo que constituam locais de encontros e de trocas materiais e simbólicas, as fronteiras continuam a impor barreiras e limites, sejam alfandegários, migratórios ou identitários, e a desencadear conflitos entre povos em contato intenso (Grimson, 2000).

O turismo, ao promover o contato entre povos distintos, estimulando trocas culturais e o confronto de identidades, cria, tal como nos territórios fronteiriços, espaços liminares, permeados de diálogos e tensões, que remetem tanto às condições do contato em si, quanto às ingerências de ordem nacional e transnacional que o tornam possível.

Nesse sentido, o que as experiências aqui expostas pretenderam demonstrar é que no estudo das interações socioculturais propiciadas pelo turismo, ademais dos aspectos da identidade, da etnicidade, do intercâmbio e mudanças culturais advindos do contato com o "outro", a experiência turística revela, e permite observar, como as relações políticas, sociais e culturais decorrentes do contato entre povos distintos, evidenciam tanto as regras e contradições próprias da experiência histórica e social interna de cada grupo, quanto refletem as determinações nacionais e internacionais mais amplas, sejam de caráter econômico ou político, que repercutem no cotidiano e na prática do contato com o estrangeiro nos espaços onde a atividade se desenvolve.

No caso do turismo na fronteira do Brasil com o Paraguai, condições históricas ditam as regras do contato, alimentadas por acontecimentos conjunturais, que conformam a dinâmica da representação 
e da relação com a alteridade, que é ao mesmo tempo o vizinho e o estrangeiro. Políticas nacionais e internacionais, como a ocupação do território paraguaio por produtores de soja brasileiros, acabam por definir novas visões e relações dos paraguaios com os turistas e os próprios moradores de Ponta Porã. Ao mesmo tempo, o comércio de produtos importados e o contato com a tecnologia globalizada, induz no habitante do território paraguaio, uma nova percepção de mundo e de si mesmo, trazendo novos parâmetros para o diálogo entre povos e identidades nesse espaço fronteiriço.

Cabe destacar, por fim, que o turismo, tal como os territórios de fronteira, ao mesmo tempo em que demonstra ser um fenômeno propiciador de intensas relações interculturais, implicando em trocas materiais e simbólicas, constitui-se também num ambiente de tensão e de contradições sociais. A experiência do contato propiciada pelo turismo é uma circunstância de permanentes negociações identitárias e políticas, um contexto marcado por uma linha tênue entre o intercâmbio e o conflito de idéias e valores históricos, sociais e culturais.

\section{Bibliografia}

Albuquerque, José Lindomar C.

2009 A dinâmica das fronteiras: deslocamento e circulação dos "brasiguaios" entre os limites nacionais. Horizontes Antropológicos, v. 31: 137-166.

Banducci Jr, Álvaro e Romero, Arnaldo 2005 "Culto aos mortos na fronteira entre o Brasil e o Paraguai; os rituais da Sexta-Feira Santa em Pedro Juan Caballero". In Oliveira, Tito Carlos M (org.). Território sem limites: estudos sobre fronteiras Campo Grande: UFMS, .

Banducci Jr., Alvaro e Amizo, Isabella.B. 2009 As fronteiras da tradição: os rituais e a religiosidade dos estacioneros em diferentes cidades do Paraguai. Anais do III Simpósio Internacional sobre Religiosidades, Diálogos Culturais e Hibridações, Campo Grande (MS) :
Ed. UFMS.

Barth, Frederik

1998 "Grupos étnicos e suas fronteiras". In Poutignat, Philippe e Streiff-Fenart, Jocelyne (org) Teorias da Etnicidade; seguido de Grupos étnicos e suas fronteiras. São Paulo : UNESP.

Canclini, Néstor G.

1998 Culturas Híbridas: estratégias para entrar e sair da modernidade. São Paulo: Edusp, 1998.

Cardoso de Oliveira, Roberto de e Baines, Stephen G. (orgs.).

2005 Nacionalidade e etnicidade em fronteiras. Brasília: Universidade de Brasília.

Grimson, Alejandro (comp.)

2000 Fronteras, naciones e identidades, la periferia como centro. Buenos Aires : Ed. CICCUS/ La Crujía.

Grimson, Alejandro (comp.)

2005 "Cortar puentes, cortar pollos: conflictos económicos y agencias políticas en Uruguayana (Brasil) - Libres (Argentina)". In Oliveira, Roberto C. de e Baines, Stephen G. (orgs.). Nacionalidade e etnicidade em fronteiras. Brasília: Universidade de Brasília, p. 21- 53.

Grimson, Alejandro, Ribeiro, Gustavo L. e Seman, Pablo (comp.).

2004 La antropologia brasileña contemporânea, Contribuiciones para um diálogo latinoamericano. Buenos Aires: Prometeo Libros.

Hannerz, Ulrich

1997 Fluxos, fronteiras, híbridos: palavras-chave da antropologia transnacional. Mana 3 (1) Rio de Janeiro.

Lamberti, Eliana e Oliveira, Tito Carlos M.

2008 "As trocas, a territorialidade e o ambiente na fronteira Ponta Porã (Brasil) e Pedro Juan Caballero (Paraguai)". In Osório, Antônio C. N.; Pereira, Jacira H. V. e Oliveira, Tito C. M. (orgs). América Platina: educação, integração e desenvolvimento territorial. Campo Grande-MS: Ed. UFMS.

Marin, Jerri R.

2000-2001 Fronteiras e fronteiriços: os intercâmbios cultuais e a nacionalização da fronteira no Sul do Estado de Mato 
Grosso. Fronteiras, Revista de História. Campo Grande - MS : UFMS, 4/5, (7/9): 157-182.

Martins, Patricia C. S.

2007 A formação do território turístico de Pedro Juan Caballero (Paraguai). Dissertação. Mestrado em Geografia. Aquidauana (MS) : UFMS

Masi, Fernando

2008 "América Latina: la integración en la disyuntiva". In Osório, Antônio C.N.; Pereira, Jacira H. V. e Oliveira, Tito C. M. (orgs). América Platina: educação, integração e desenvolvimento territorial. Campo Grande - MS: Ed. UFMS, v. II.

Müller, Karla M.

2005 "Espaços e fronteiras internacionais, pólos de integração" In Oliveira, Tito C. M.. (org.). Território sem limites: estudos sobre fronteiras. Campo Grande: UFMS.

Oliveira, Tito C. M..

2005 "Tipologia das relações fronteiriças: elementos para o debate teórico-práticos” In Oliveira, Tito C. M. (org.). Territórios sem limites: estudos sobre fronteiras, Campo Grande: UFMS.

Raffestin, Claude.

2005 "A ordem e a desordem ou os paradoxos da fronteira" In Oliveira, Tito Carlos. (org.). Território sem limites: estudos sobre fronteiras. Campo Grande: UFMS.

Souza, José C. de.

1997 O fenômeno da migração paraguaia no século XX. Fronteiras: revista de História. Campo Grande - MS ; Ed. UFMS.

Sahlins, Peter

2000 "Repensando Boundaries" In Grimson, Alejandro (comp.) Fronteras, naciones e identidades; la periferia como centro. Buenos Aires : Ediciones CICCUS/ La Crujía.

Sprandel, Márcia A.

2000 "Brasiguayos: uma identidad de frontera y sus transformaciones" In Grimson, Alejandro (comp.). Fronteras, naciones e identidades; la periferia como centro. Buenos Aires : Ediciones CICCUS/ La Crujía.

\section{NOTAS}

1 E. Leach, em seu estudo sobre Burma, de 1960, já problematizava a noção convencional de fronteira política (Hannerz, 1997) e, como salienta Grimson (2000:13), no livro Ritos de passagem Van Gennep nos legou um dos mais brilhantes trabalhos sobre fronteira num sentido metafórico.

2 A Guerra com o Paraguai, ou Guerra Grande, foi um dos maiores conflitos armados ocorridos na América do Sul, envolvendo o Paraguai e os países da Tríplice Aliança (Brasil, Argentina e Uruguai), seus adversários. O conflito, que durou de 1864 a 1870, desencadeou-se sobretudo em razão de disputas em torno de limites territoriais, do interesse pela navegação nos rios da Bacia do Prata e de antigas rivalidades entre os países envolvidos. O Paraguai, país protagonista da guerra, teve que enfrentar a resistência e contra-ofensiva da Tríplice Aliança, sucumbindo a suas forças no ano de 1870 , estando o país economicamente arrasado e abalado pela perda substantiva de vidas, fosse de militares ou civis, acometidos pela fome e por doenças.

3 Muito comum nas cidades paraguaias, e disseminada também por todo o Mato Grosso do Sul, a roda de tereré é uma espécie de ritual de sociabilidade, em que grupos de pessoas se reúnem periodicamente para desfrutar da bebida e manter longas e aprazíveis conversas. O tereré é uma bebida à base de erva mate, à qual se adiciona água gelada, que é sorvida com o uso de uma bomba, ou canudo de metal destinado a esse fim.

4 Chipa e sopa paraguaia constituem dois itens muito populares na culinária paraguaia, sendo a primeira uma espécie de bolo feito de queijo e polvilho e a segunda uma torta salgada de milho assada.

5 Do mesmo modo, é muito comum encontrar, em território sul-mato-grossense fronteiriço, nas pequenas cidades que fazem divisa com o Paraguai, cultos e rituais religiosos daquele povo sendo praticados por brasileiros, descendentes ou não de paraguaios, influenciados pela cultura religiosa do país vizinho. Assim, existem grupos organizados de estacioneros que atuam na cidade de Bela Vista (MS), vizinha de Bella Vista Norte (PY); há grandes celebrações dedicadas à Virgem de Caacupé, padroeira do Paraguai, em inúmeras cidades de Mato Grosso do Sul; os cemitérios de Ponta Porã e de Bela Vista abrem suas portas, na Sexta-feira Santa, para receberem visitantes paraguaios e brasileiros, que ali celebram a Paixão de Cristo; entre outras manifestações e costumes próprios do país vizinho.

6 De acordo com Sprandel (2000), as primeiras entradas de grandes proprietários de terras brasileiros em território paraguaio aconteceram na década de 1950, no início do governo de Alfredo Stroessner, ditador que presidiu o Paraguai por 35 anos, entre 1954 e 1989. Mas foi a partir da década de 1970 que a migração brasileira em direção ao Paraguai se intensificou, criando-se colônias e até cidades com população majoritariamente brasileira, tais como Santa Rita, Santa Rosa de Monday, Naranjal, San Alberto, 
entre outras.

7 A maior usina geradora de energia elétrica do mundo, Itaipu, concebida a partir de um acordo binacional Brasil - Paraguai, foi construída entre os anos de 1975 e 1982 na fronteira entre os dois países. O reservatório gerado com a instalação da usina inundou uma área de aproximadamente $1300 \mathrm{~km}^{2}$, desalojando mais de 40 mil moradores que viviam em pequenas e grandes propriedades rurais, além de vilas, situadas ao longo do rio Paraná.

8 Essas famílias, compostas de arrendatários e de trabalhadores rurais, vieram a ser conhecidas mais tarde como “brasiguaios”. Desalojadas do campo, em função da mecanização das lavouras ou e do processo de concentração das terras, em 1985 iniciam, de forma organizada, seu regresso ao Brasil, reivindicando terras e infra-estrutura para produção (Sprandel, 2000).

9 Ao trazer para a cidade as marcas dos embates no campo, os trabalhadores transferem para o contexto urbano suas disputas de identidade, fomentando as representações variadas sobre os brasileiros e os paraguaios (Albuquerque, 2009). Sem preparo técnico ou treinamento adequado para o comércio especializado, esses trabalhadores são absorvidos pelo mercado informal, como o pequeno comércio e atividades como as de camelôs ou ambulantes, que os coloca numa situação de marginalidade, exigindo novas e penosas formas de integração, acirrando os conflitos no contexto da fronteira.

Recibido:

Sometido a evaluación por pares anónimos 